\title{
TYPES OF SPEECH STYLE PERFORMED BY THE CHARACTERS IN BIRDS OF PREY MOVIE
}

\author{
Ni Made Diah Cahyani ${ }^{1}$, Ni Made Verayanti Utami², I Wayan \\ Juniartha ${ }^{3}$ \\ Mahasaraswati Denpasar University, Indonesia ${ }^{123}$ \\ diahcahyani1999@gmail.com,_ｖerayanti.utami@unmas.ac.id, \\ jjuniartha@gmail.com
}

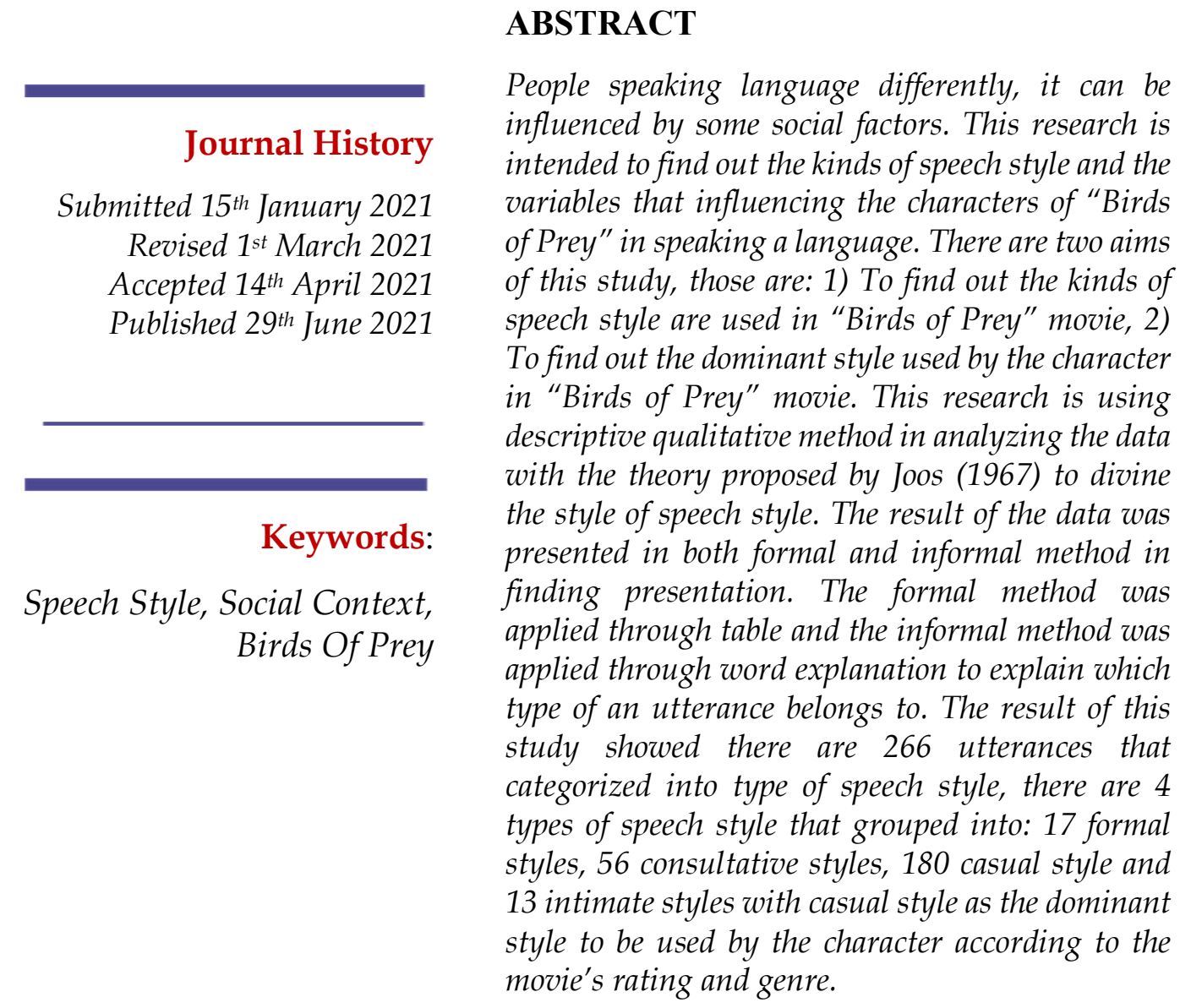

INTRODUCTION

People communicate through language as the main media (Makoelle, 2020).Language has played a significant role in how people deliver as well as receiving such an in their lives. Language also encourages 
people to build a discussion without any difficulties, and language also enables people to socialize in a very efficient way. According to (Chaika, 1982) society and language are two distinct objects which have a close connection with their uses in real-life behavior and cannot be implemented without each other. More precisely, society is the place where language can be applied and that no contact may occur without the two sides of both languages and society. Sociolinguistics is a study of the use of language in context, especially in society, according to (Hasan, Yoke, \& Jangga, 2018). Sociolinguistics, in a broader view, incorporates the principle of sociology that speaks of social activity as well as the relation within a group and linguistics that concern how language is built. The association between language and society has made the variation of language usage close to the explanation why dialect or accent is different in certain countries, because society has played a significant role in shaping the way people communicate. In short, sociolinguistics developed the language varieties to be used and style to be modified in different contexts that were built by social characteristics such as age, level of education and history.

Not only is it fashion with a style, but the way language is spoken also has many styles according to its social context, such as age, gender, education, race, status etc. According to Chaika (1982:29), the verbal structure played a significant role in referring to the language style. The way we speak should depend on the context, who we are talking about and whom we are talking to. Listening to each other is the most important (Lestari, 2016). That is precisely why the role of speech style here is profoundly discussed. The type of speech can also be defined by the social standing of individuals. For example, the way we talk to those below our age will be somewhat different from the way we talk to elders. When someone is doing the opposite, the style of speech style is misapplied.

The researcher used a movie to search for the details to evaluate the speech styles. Movie is a visual media that is usually targeted by people in learning English or any other languages. It is also regarded as a social and cultural art that carries knowledge (Liu, et al., 2020). Instead of reading, movie allows students to find appealing inspiration and curiosity. The popularity of movie being perceived world-wide. In 2016, the revenue of the global box office reached $\$ 38.6$ billion on their own (Bowes, Watts, Costello, Murphy, \& Lilienfeld, 2018). Aside from its entertainment aspect, learning through movie makes our brain to be more active especially in analyzing the language style. There are several famous movies that become the data base in doing a research. Birds of Prey is one of the most awaited movie in 2020 that has earnt $\$ 201$ million worldwide and became the sixth highest-grossing of 2020 recorded in Wikipedia.com. Birds of Prey is a super hero action movie produced by DC comics. The lead role as Harley Quinn was taken by Margot Robbie. She was a certified psychiatrist who became 
a crazed criminal and fell in love with her patient, Joker. She also a member of the Suicide Squad headed by her boyfriend Joker. This film started with the frustration of Harley Quinn after breaking up with Joker. Shortly thereafter, she finally back on her feet and began chattering right there and then, and then met with a few other criminal women like Huntress, Renee Montoya and Black Canary and little did she knew that ever since then they have been a gangster fighting for the emancipation of women in Gotham City. Their journey did not seem easy because they have to fight against a lord criminal Roman Sionis along with his men.

This research takes speech styles as a focus, since a suitable style should be considered thoroughly when speaking, so that people can talk easily and prevent a poor impression due to a wrong style in a certain situation. In addition, the researchers would like to look and examine the speech style the characters of the movie Birds of Prey use since a lot of people watch it but do not pay attention whether or not the characters are using a proper style. So, with the theory from Joos (1967) that has classified speech style into five categories which are frozen style, formal style, consultative style, casual style and intimate style and with the combination of sociolinguistics to get a better understanding in its social context could make the viewers understand and take embrace to why speech style is matter and required to be used properly. Therefore, according to some related study previously, the style in uttering a speech can be varies according to its social context and also the factors that influenced the speaker in using it and it is important to classified them in proper way.

\section{METHODS}

This research used Birds of Prey as the field to find the data in the conversation that is spoken by the characters. The movie that produced by Margot Robbie, Bryan Unkeless along with Sue Kroll and directed by Cathy Yan was released on January 25th, 2020 in Mexico City and February 7th, 2020 in United States with 109 minutes long and its achievement to gain \$201 million worldwide made it the sixth highest-grossing movie in 2020 recorded in Wikipedia.com.

A descriptive qualitative method is used to describe and explain the data that has been collected. Therefore, the main instrument is the utterances of the characters in Birds of Prey movie that collected by watching the movie first then match it with the transcript to avoid human error. The collected data was classified first into five classification of speech style with the theory proposed by Joos (1967) before analyze it based on the characteristics of speech style so that it is provided a clear result to which style an utterance belongs to. 
The data presentation was done by providing an explanation descriptively. Both formal and informal method were used in finding presentation. Formal method was used to provide the data in table form, show the percentage as well as the frequency of each style appeared. Informal method was used to present the data that has been collected in order to make a wider view for the reader through written explanation.

\section{RESULTS AND DISCUSSION}

\section{RESULT}

This research was conducted with the aim to find out the types of speech style that are used by the characters in Birds of Prey movie. Other than that, the dominant type which most likely to be used by the characters was also the problem the researcher aimed to solve. There were only four out from five types of speech style found in Birds of Prey movie that can be seen in the table below:

Types of Speech Style

\begin{tabular}{cccc} 
No & Types & Frequency & Percentage \\
\hline 1 & Frozen & - & - \\
\hline 2 & Formal & 17 & $6.39 \%$ \\
\hline 3 & Consultative & 56 & $21.05 \%$ \\
\hline 4 & Casual & 180 & $67.67 \%$ \\
\hline 5 & Intimate & 13 & $4.89 \%$ \\
\hline & Total & 266 & $\mathbf{1 0 0 \%}$
\end{tabular}

According to the table above, a total of 266 data were collected. Formal style occurred for 17 times equal to $6.39 \%$, consultative style occurred for 56 times equal to $21.05 \%$, casual style occurred for 10 times equal to $67.67 \%$ and intimate style occurred for 13 times equal to $4.89 \%$. Entirely discussed, the characters of Birds of Prey movie were using a casual style most of the time, it is due to its setting, where many ordinary practices are kept that do not need a strict style to talk in and which are helped as a backdrop by the urban world with the participation of certain places like night clubs, the street and some houses of the characters. On the other hand, frozen style did not appear at all because there was no special occasion that encouraging the characters to use a very formal style of speech. 


\section{DISCUSSION}

The discussion only given several representations to illustrate each form of speech style with a total of 6 data that can be seen as follows:

\section{FORMAL STYLE}

According to Joos (1967) formal style is the style used in formal occasion, where at least one context should be shared or otherwise would be well known. This style is well established in a complete, logically sequenced and strongly consistent expression with a clear structure of word use.

\section{Datum 1}

These are serious accusations, Miss Montoya.

According to Datum 1 above, the utterance belongs to formal style. It can be seen clearly from the context that the one who was speaking was the head of the place where Montoya is working. If we see from the setting, the place where they do the conversation was still in working area where formality is highly required to communicate towards each other especially for the boss that carry an authority as well as to proof that he is a professional person by the way he talk since public speaking could be the proof what a typical person someone is. Other than the setting, the context of what they were discussed about could be the point that his utterance belongs to formal style. As what has been mentioned above, the topic was all about business since they were in a working place which made him speaking formally. Furthermore, the way the sentence was built also made it belongs to formal style. Formal style has a well-constructed sentence with perfect grammatical and a good word choice that well applied in the utterance above by the use of words 'accusations' which originally mean a claim that somebody has done something illegal.

\section{Datum 2}

\section{Can I help you?}

The officer was using a formal style on his speech above since he was on duty. In a normal operational practice, a formal style in speech also demanded both reverence and discipline for the relevant firms. The official's formal style can be marked by the use of the 'can.' And it was also grammatically correct. Joos (1967) says that the formal style can also be used for referring to outsiders away from its goal of using it for the large audience. The officer was motivated by the addressee's discussion of a robbery with Harley Quinn and his role was to represent the visitor by speaking formally. In the use of formal style of speech, the atmosphere was often influenced by the officer while he was still in the workplace and during his service. Other than that, the subject on which Harley Quinn was 
about to report a sensitive matter prompted the officer to talk as formally as possible to keep the dialogue going well and feel comfortable with the speaker.

\section{CONSULTATIVE STYLE}

According to Joos (1967) consultative style is a style typically used in a state where we speak the same language to the outsiders but share little of the context of each other. The consultative style is generally used in semiformal circumstances in which the formality is required however it is acceptable to be a little bit level down to casual style.

\section{Datum 3}

\section{Okay, fine, so I hadn't told people about the breakup}

The utterance that was spoken by Harley Quinn above is considered as consultative style. Unlike the others that speaking to the other character in the movie, Harley as the main character that carry the point of view all along the way has an ability to speak to the viewers. The context that built above was that Harley spoke to people that considered close to her and have already known her background however she still need to watch her manner and speaking properly as to what consultative stands for that allow the speaker to be less formal but still keeping the limit of formality. If we see from the construction of the words, consultative tends to be shorter than formal style which allow the use of omission, word choice and etc. as long as it still appropriate and fit the context such as the use of word 'okay' from 'OK' which probably derived from the word orl correct which mean all correct literally to express an agreement however that word can be changed to 'all right' for a formal occasion. In addition, the use of 'hadn't' also made the utterance belong to consultative style since the original words 'had not' has modified into a shorten version.

\section{Datum 4}

I've never been. I've heard it's beautiful.

The Black Canary was the person of the above speech. What she has said is regarded as a style of consulting. At their first private meeting together, the way she responded to Roman's question was calm enough. On the scene, she worked in his club as a singer and got a promotion to be the private driver of Roman. Before then, the two of them had never spoken to each other, but they were not an outsider who had to navigate the formality when thinking of something light. The words she used were kind of semiformal choices where she preferred to utter the shorter term rather than the full and well-constructed expression, such as 'I have never been going to Chongo-Kinshasa (the place Roman was asking whether or not the Black Canary ever visited). The use of formal types was too restrictive for her to 
use, since she often knew him when she employed in his club and it was too inadequate to use informal styles because of the fact that they lacked a shared denominator.

\section{CASUAL STYLE}

According to Joos (1967) casual style is a style used but also suitable and desired for a casual environment, such as in a group of friends or coworkers. No perfect grammar or standardized sentence is necessary so that it is allowed to use slang, omission, repetition, etc.

\section{Datum 5}

and no one gives two shits, who we are beyond that.

The Datum 5 is perceived to be a casual style, based on the speech given by Harley Quinn above. The discussion took place in a night club with noisy music and drinks involving an audience. In that club, Harley was a regular customer and Dinah Lance, who served as a musician, was often known as Black Canary. They got along very well and much better helped them appreciate each other. Harley used the informal style of the words 'two shits' in the film, which did not mean being taken literally. The original term 'care' was intended to be modified because it sounds more normal and suits the location and circumstance where the dialogue existed. The factor for which Harley spoke was the element that affect her voice. Since they are both on the same age, it persuaded her to chat with her friend casually. Furthermore, the chance they were all in the club and had a little fun with Harley was already a justification for shaping her expression in a relaxed style. Looking at the subject, it can also be the reason why her style is inspired to be casual style by the phrase 'who we are beyond that' which considered to be the topic that familiar to the both of them and did not require formalities in discussing it.

\section{Datum 6}

\section{I want that kid out of my fucking house!}

The above talk was talked by foster parents of Cassandra Cain, the particular dad who fought against her. The manner in which they speak is known as informal. According to Joos, in 1967, the informal form often includes slang terms that can be observed in the expression using 'fucking' aside from a not particularly well-designed sentence. But if the term fucking has collapsed, the situation they have mentioned is always called casual. It's a casual type. Besides, they are both husbands and wives and much of the time they use relaxed style because of their large amount of mutual history and making contact simpler. Cassandra's father used his speaking informal style, as he was more influenced by the addressee. His mom was someone he yelled at. Naturally, someone uses casually a lot to get a great 
environment to chat to someone known to be the nearest person in particular to his wife and simply because casual style will show that the speaker is relaxed with the speaker. Besides this, the subject which was discussed was called extremely casual, which was about a child they never desired and began to criticize one another.

\section{INTIMATE STYLE}

According to Joos (1967) an intimate style may be very brief or different, but generally it has a special sense that both parties know and include elliptical characteristics, deletion, no-verbal communication and code, and usually this kind of style is used in situations between those who have known each other well or can be described as a private style.

\section{Datum 7}

Here's the thing, Romy baby, your protection is based on the fact that people are scared of you. Just like they're scared of Mr. J.

The Datum 7 above is considered as intimate style. Harley Quinn is the one who uttered the speech above. From the setting of place where the conversation occurred, it was in a very private place where only the two of them that capable to hear to the discussion. As to the characterization of intimate style itself, it usually occurred between people that has already known each other more than anyone else and that could tell the relation Harley has with Roman to make them use an intimate style. Other than the relation they have, the topic that was carried out along the talk also made it belong to intimate style since there was also a mention of $\mathbf{M r}$. J used as code that only the two of them understand what it means due to Harley found an alternative to say someone's name however still made the conversation understandable for both parties. In addition, the nick name Harley created for Roman, Romy baby, was also targeted to make the whole utterance belongs to intimate style that nobody has ever called him that way.

\section{Datum 8}

You soothe me, little bird.

e spoke intimately with the Black Canary, it also was helped by his gesture which embraced her, in the utterance spoken by Roman above. Roman used a nick name that he made for her, 'little bird,' particularly on the stage. In his lifespan, the Black Canary is one of the nearest person for Roman not to mention his secretary, Victor. The Black Canary was preparing to go before this, and Roman didn't want that to happen and uttered 'you relax me' expression that he felt was private, because only the two of them understood what all of it was and also decided to deter her from going. Since the one he spoke to was the Black Canary, that most likely prompted him in his speech to use an intimate style and to use it more 
confidently with those he valued the most. The degree of closeness they have, thus, has made the subject as intimate as the gesture and has also influenced it. While embracing her, Roman ordered her to stay and uttered a compliment to strengthen his encouragement.

\section{CONCLUSION}

After completing the study of speech style in the Birds of Prey film with the theory suggested by Joos (1967) in the classification of speech styles, it has been found that there are only four types that occurred in the movie those are, formal style, consultation style, casual style and intimate style with casual style is the dominant type used by the characters with the percentage of $67.67 \%$ out from $100 \%$. The style that most frequently occurs is casual and accompanied by a consultative style because of the presence of duty tasks, according to the movie itself which mostly shows daily activities in real life. DC production usually offers a scene of battling or abusive use of cursing words in their production especially in Birds of Prey, because of its rating of 15 by the British Film Classification Board (BBFC), for abuse, sexual presence and substance items so that only persons over the age of 15 years may watch the movie. The movie attempts to prove to the viewers by using casual styles in most of the scene that even though Birds of Prey is viewed as action movie featuring a lot of battle scene it can be more enjoyable and that casual style can help the audience reveal all the odd and unexpected scene such as the leg breaking, abduction and devastation of the public places.

\section{REFERENCES}

Bowes, S. M., Watts, A. L., Costello, T. H., Murphy, B. A., \& Lilienfeld, S. O. (2018). psychopathy and entertainment preferences: clarifying the role of abnormal and normal. Personality and Individual Differences, 129, 33-37. doi:https:// doi.org/10.1016/j.paid.2018.03.009

Chaika, E. (1982). Language the social mirror. California: Newbury House, 1982.

Hamdany, M. A., \& Damanhuri. (2017). Speech Style Used in the Workplace in 500 Days of Summer Movie. Retrieved from https://jurnalmahasiswa.unesa.ac.id/index.php/languagehorizon/article/view/18260

Hasan, N. H., Yoke, C. S., \& Jangga, R. (2018). A multifactorial sociolinguistic analysis of SME business company naming in Malaysia. Procedia Economics and Finance, 31, 228-236. doi:https:/ / doi.org/10.1016/S2212-5671(15)01224-1 
Joos, M. (1967). The five clocks. Houghton Mifflin Harcourt P.

Lestari, D. (2016). Enhancing Listening Skill of Young Learners through Videomagic English. International Journal of Research in Social Sciences, 6(2), 7-13.

Liu, Q. B., Gao, S., Guo, B. F., Liu, H., Feng, Y. Z., \& Xia, H. (2020). research and development of movie social system. Procedia Computer Science, 166, 154-159. doi:https:/ / doi.org/10.1016/j.procs.2020.02.039

Makoelle, T. M. (2020). language, terminology, and inclusive education: a case of kazakhstani transition to inclusion. Sage Journals, 10. doi:https://doi.org/10.1177/2158244020902089

Putra, E. T., \& Rosa, R. N. (2019). The Analysis of Speech Style Used by Ellen Degeneres in Ellen Talk Show. Retrieved from http://ejournal.unp.ac.id/index.php/jell

Wani, S. (2013). A Sociolinguistic Analysis of Style of Speech as Performed by Young Adult Girl Characters in Judy Blume's are You There God? It's Me, Margaret. Retrieved from https://journal.unhas.ac.id/index.php/jish/article/view/9858/58 52 